\title{
Applying Response Surface Methodology to optimize the decarbonization process of Timahdit oil shale
}

\author{
Laila Makouki ${ }^{1, *}$, Meriem Tarbaoui ${ }^{1}$, Samia Glissi ${ }^{1}$, Said Mansouri ${ }^{1}$, Hassan Hannache ${ }^{1,2}$ and \\ Mina Oumam ${ }^{1}$ \\ ${ }^{1}$ LIMAT-Thermostructural Materials and Polymers Team, Faculty of science Ben M'sik, University Hassan II of \\ Casablanca, Boulevard Cdt Driss Harti, BP.7955, Ben M'sik, Casablanca, Morocco \\ ${ }^{2}$ Center of Advanced Materials, EMINES, University Mohammed VI Polytechnic, Lot 660 Hay Moulay Rachid, \\ 43150, Ben Guerir, Morocco
}

\begin{abstract}
The present article aims to optimize the decarbonization of Timahdit oil shale layer $\mathrm{Y}$ by removing carbonates from the raw rock using acetic acid. The response surface methodology "central composite design (CCD)" has been used as a method of optimization to study the 3 factors of the process. The factors studied are the concentration of the acid, the processing time, and the ratio (liquid/solid). The optimal conditions with $68.17 \%$ of residue rate are obtained with $2 \mathrm{~mol} / \mathrm{l}$ as concentration, $120 \mathrm{~min}$ as a time of treatment and 10.02 for the ratio.

The raw (Y) and optimized materials (YO) were characterized by Scanning Electron Microscopy (SEM), Xray fluorescence $(\mathrm{XRF})$ and $\mathrm{X}$-ray diffraction $(\mathrm{XRD})$. The results showed that the acetic acid used to remove carbonates affects the chemical composition and the texture evolution of the residues.
\end{abstract}

Keywords: Decarbonization; oil shale; response surface methodology; central composite design.

\section{Introduction}

The global economic development places high demands on energy resources. Oil shales are an interesting energy reserve, and their distribution in the world is more homogeneous than oil or natural gas ${ }^{1,2}$. World reserves are estimated at 2000 trillion barrels of oil ${ }^{3}$ distributed in more than 50 countries. Witch Morocco is ranked into the 7th rank after the USA, Russia, the Democratic Republic of Congo, Brazil and Italy with a potential of 53 billion barrels of oil. Which more than 37 billion barrels are in the two main deposits: Timahdit and Tarfaya ${ }^{2,4}$.

Oil shale as a kind of alternative fuel resource has attracted the attention of many researchers, so several studies have been carried out on Moroccan shale oil; mainly those of the deposits of Tarfaya and Timahdit ${ }^{5}$. Oil shale is a complex mixture of organic and inorganic materials. The inorganic components mainly include carbonates, silicates, and pyrite minerals, as well as trace elements (As, B, Mo, Ni, $\mathrm{Zn}, \mathrm{Ti}$, etc.). The organic part includes kerogen and small quantities of bitumen ${ }^{6-8}$.

Most of the studies had as their main objectives, the development and the valorization of oil shale as an exploitable resource as much as natural resources, in various more applied fields ${ }^{9-11}$, such as the

*Corresponding author: Laila Makouki

Email address : makoukilaila@gmail.com DOI: http://dx.doi.org/10.13171/mjc8519070271m development of oil shale applications in the fields of adsorbent materials for the decontamination of effluents. The major advantage of such applications in the development of adsorbents lies in the availability of this material and its composition rich in organic matter (carbon source) intimately linked to a mineral matrix. In this paper, we focus on one of the stages of preparation of carbon adsorbents, called: decarbonization.

\section{Materiel and method}

\section{Decarbonization process}

The oil shale used in this work was collected from the layer $\mathrm{Y}$ of Timahdit (Middle Atlas), Morocco. The oil shale was crushed and sieved to a particle size of $\leq 0.5 \mathrm{~mm}$. The homogeneous powder obtained was decarbonated with acetic acid. First, $10 \mathrm{~g}$ of the raw oil shale (Y) was stirred with solutions of $\mathrm{CH} 3 \mathrm{COOH}$ at different concentrations, different treatment durations and different ratios $(1 / s)$. Then the residues obtained (YA) after filtration were washed with distilled water to neutral $\mathrm{pH}$. Then they were dried in an oven for 24 hours at a temperature of $80{ }^{\circ} \mathrm{C}$. The residue yield after decarbonization was determined by using the following equation:

Received April 25, 2019

Accepted June 11, 2019

Published July 2, 2019 
Residue yield $(\%)=\frac{W c}{W 0} \times 100$

Where $\mathrm{W}_{\mathrm{C}}$ is the dry weight $(\mathrm{g})$ of final decarbonated material and $\mathrm{W}_{0}$ is the dry weight $(\mathrm{g})$ of the precursor.

\section{Chemicals}

The acetic acid used in this study was of analytical grade, and the solutions were prepared using distilled water.

\section{Materials characterization and instrumentation}

The characterization of the raw and optimized materials was determined with the help of spectroscopic and quantitative analysis: Hirox SH3500MB performed scanning electron microscopy (SEM) analysis. Bruker D2 Phaser realized X-ray diffraction (XRD) analysis, and EPSILON 3 XL PANalytical performed the X-ray fluorescence (XRF) analysis.

\section{RSM and CCD statistical optimization}

RSM is an applied statistical technique that is used for the optimization of the effects of process variables on the properties of prepared products using a combination of mathematical and statistical approach ${ }^{12}$. In this research, CCD, which was a subcomponent of RSM, was used to determine the optimum process variables for decarbonization of Timahdit oil shale using acetic acid as a decarbonization agent. The CCD was used for fitting a second-order model, which requires only a minimum number of experiments for modeling ${ }^{13}$. The CCD consists of $2 \mathrm{n}$ factorial runs (coded to the usual \pm notation) with $2 \mathrm{n}$ axial runs $( \pm \mathrm{a}, 0,0, \ldots, 0)$, $(0, \pm \mathrm{a}, 0,0, \ldots, 0), \ldots,(0,0, \ldots, \pm \mathrm{a})$ and accentor runs (six replicates, $0,0,0, \ldots, 0)$. The number of factors $n$ increases the number of runs for a complete replicate of the design, which is given in Eq. (2).

$\mathrm{N}=2^{\mathrm{n}}+2 \mathrm{n}+\mathrm{n}_{\mathrm{c}}$

The optimization process involves three major steps: (1) performing the statistically designed experiments, (2) estimating the coefficients in a mathematical model, and (3) predicting the response and checking the adequacy of the model ${ }^{14-18}$. An empirical model was developed to correlate the response to the decarbonization process and is based on second-order quadratic model for decarbonization of Timahdit oil shale using acetic acid as given by Eq. (3) in order to analyze the effect of parameter interactions ${ }^{19}$.

$Y_{i}=b_{0}+\Sigma b_{i} X_{i}+\Sigma b_{i i} X i^{2}+\Sigma b_{i j} X_{i} X_{j}+£_{i}$

Where $\mathrm{Y}_{\mathrm{i}}$ is the response variable, $\mathrm{b}_{0}$ is the constant of the model, $b_{i}$ is the effect of factor $X_{i}, b_{i j}$ is the effect of the interactions between factors $X_{i}$ and $X_{j}, b_{i i}$ is the quadratic effect of factor $X_{i}$ and $£_{i}$ is the residue.

\section{Model fitting and statistical analysis}

The statistical software package Design-Expert, JMP 7, was used for regression analysis of experimental data to fit the equations developed and also to plot desirability curves. ANOVA was used to estimate the statistical parameters.

\section{Results and Discussion}

\section{Experimental design Methodology}

Matrix of experiments and realization of tests

The results obtained in a previous screening study allowed us to choose the most influential variables on the decarbonization of the layer $\mathrm{Y}$ of Timahdit oil shale, namely the concentration of acetic acid used, the duration of decarbonization process and the ratio (liquid (acetic acid solution)/solid (Crushed oil shale)). This work will be devoted to the optimization of the decarbonization process using composite centred design (CCD). This later was utilized for the development of correlations between the dependent variables (factors) and independent variables (responses). The factors and their field of study are shown in (Table 1). The studied response is $\mathrm{Y}$ : the residue yield after decarbonization. Runs 8, 9, 10 and 11 at the center point were used to determine the experimental error. The experimental factors and their levels are presented in (Table 1). The matrix of the experiments and the results are presented in (Table 2).

Table 1. Experimental factors and levels in the central composite design.

\begin{tabular}{|l|c|c|c|}
\hline Factors & Lower level (-1) & Central points (0) & Higher level (+1) \\
\hline Concentration (mol/l) $\mathbf{( \mathbf { X } _ { 1 } )}$ & 1 & 2 & 3 \\
\hline Time $(\mathbf{m i n})\left(\mathbf{X}_{\mathbf{2}}\right)$ & 290.3 & 540 & 789.7 \\
\hline Ratio $\left(\mathbf{X}_{\mathbf{3}}\right)$ & 8.041 & 12.5 & 16.959 \\
\hline
\end{tabular}


Table 2. Experimental design matrix and results.

\begin{tabular}{|c|c|c|c|c|c|}
\hline \multirow[t]{2}{*}{ Run } & \multirow[t]{2}{*}{ Coded level } & \multicolumn{3}{|c|}{ Actual level of variables } & \multirow[b]{2}{*}{ Residue yield (Y) } \\
\hline & & Concentration $\left(\mathrm{X}_{1}\right)$ & Time $\left(\mathrm{X}_{2}\right)$ & Ratio $\left(\mathrm{X}_{3}\right)$ & \\
\hline 1 & $00 \mathrm{a}$ & 2 & 540 & 5 & 68.56 \\
\hline 2 & --- & 1 & 290.3 & 8.041 & 72.2 \\
\hline 3 & +-- & 3 & 290.3 & 8.041 & 68.03 \\
\hline 4 & -+- & 1 & 789.7 & 8.041 & 71.92 \\
\hline 5 & ++- & 3 & 789.7 & 8.041 & 68.12 \\
\hline 6 & $0 \mathrm{a} 0$ & 2 & 120.06 & 12.5 & 68.25 \\
\hline 7 & $\mathrm{a} 00$ & 0.32 & 540 & 12.5 & 79.58 \\
\hline 8 & 000 & 2 & 540 & 12.5 & 68.07 \\
\hline 9 & 000 & 2 & 540 & 12.5 & 68.03 \\
\hline 10 & 000 & 2 & 540 & 12.5 & 68.06 \\
\hline 11 & 000 & 2 & 540 & 12.5 & 68.02 \\
\hline 12 & $\mathrm{~A} 00$ & 3.68 & 540 & 12.5 & 67.22 \\
\hline 13 & OA0 & 2 & 959.94 & 12.5 & 68.16 \\
\hline 14 & --+ & 1 & 290.3 & 16.959 & 72 \\
\hline 15 & +-+ & 3 & 290.3 & 16.959 & 68.12 \\
\hline 16 & -++ & 1 & 789.7 & 16.959 & 72.2 \\
\hline 17 & +++ & 3 & 789.7 & 16.959 & 67.35 \\
\hline 18 & OOA & 2 & 540 & 19.99 & 68.01 \\
\hline
\end{tabular}

\section{Evaluation of the quality of the model}

The essential characteristics of the adjustment of the quadratic model are given in (Table 3). The regression is illustrated by the graph of the responses measured as a function of the estimated responses, which show the distribution of points around the regression line (Figure 1). The coefficient of determination $\mathrm{R}^{2}$ is 0.95 close to 1 ; this indicated that the direct effects of the factors explained more than $95 \%$ of the variation observed. Therefore, the choice of quadratic model to the modeling of decarbonization process was good. In the presence of several explanatory variables, we use the adjusted coefficient of determination $\mathrm{R}^{2}$ (adjusted $\mathrm{R}^{2}$ equals $88 \%$ ), which confirm a good fit of the model and that the descriptive quality of the postulated model is satisfactory.

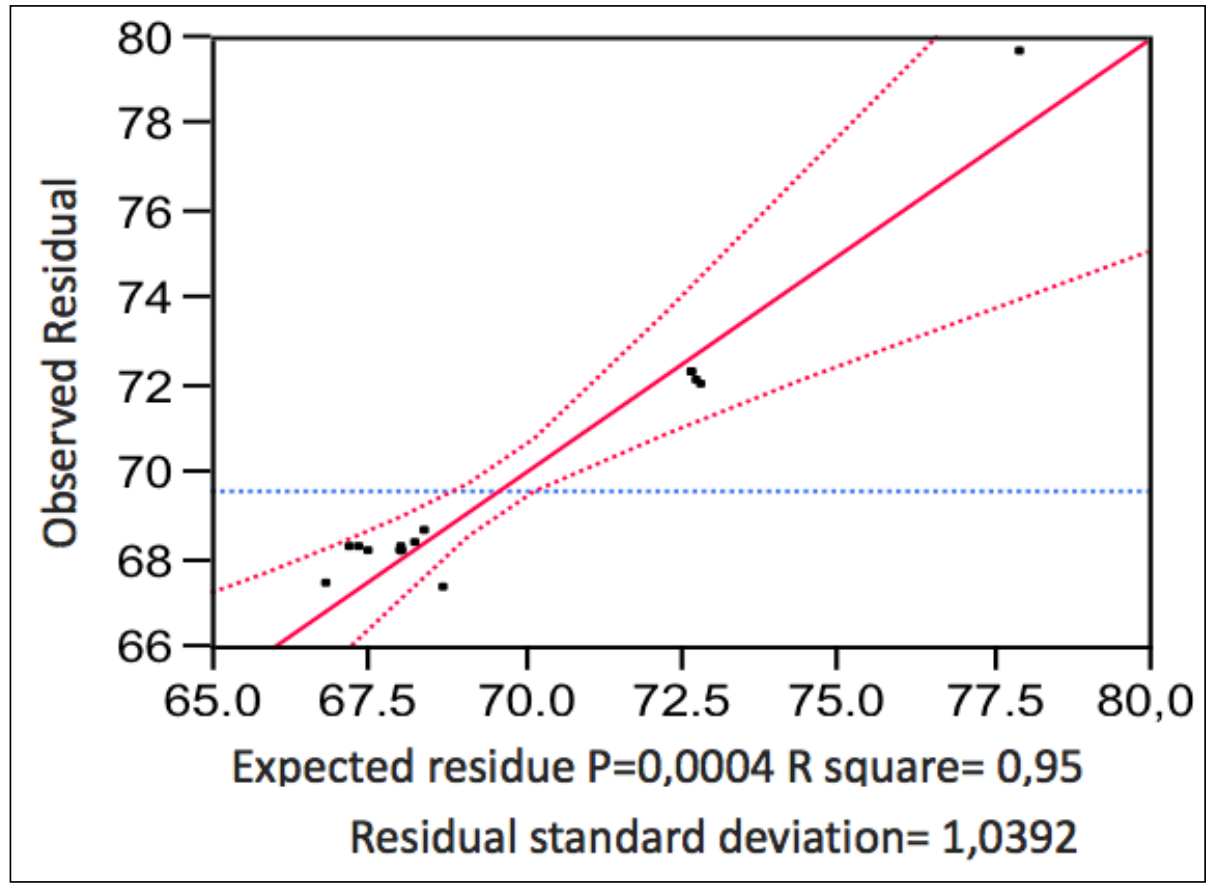

Figure 1. Graphical representation of observed values as a function of predicted values 
Table 3. Adjusted regression of the model

\begin{tabular}{|l|c|}
\hline R square & $\mathbf{0 . 9 4 6}$ \\
\hline Adjusted R square & 0.885 \\
\hline Residual standard error & 1.039 \\
\hline Average response & 69.55 \\
\hline Observations (or weighted sums) & 18 \\
\hline
\end{tabular}

\section{Analysis of variance (ANOVA)}

The validation of the quadratic model for the decarbonization process of Timahdit oil shale was performed using the model analysis of variance (ANOVA) and the method of the absence of adjustment analysis, also called analysis bias. ANOVA was used to assess the variance of the model established about the variance of the residue, using the test "Fisher Snedecor", the result was considered significant if $\left(F_{\exp }>F_{\alpha}, v_{\bmod }, v_{\text {res }}\right)$, where $\alpha=0.05^{[20]}$. According to the result of the ANOVA test, analysis of the experiment gives a factor $\mathrm{F}_{\exp }=$ 15.47. The theoretical values determined according to the table of Fisher Snedecor (for $v_{\text {model }}=9, v_{\text {residue }}$ $=8$ and confidence level $=95 \%$ ) was $\mathrm{F}_{\alpha}, v_{\bmod }, v_{\text {res }}=$ $\mathrm{F}_{0.05,9,8}=3.39$. This theoretical factor was much lower than the experimental factor, $F_{\exp }=15.47>>$ $\mathrm{F}_{\text {theo }}=3.39$. The results of the lack of adjustment of the analysis indicate that the $\mathrm{p}$-value was largely less than 0.05; these analyses were determined using the JMP7 software. The obtained results are shown in (Table 4). The results of the ANOVA test and the lack of adjustment showed that the quadratic model established was validated.

Table 4. Analysis of variance (ANOVA) determined by the JMP software.

\begin{tabular}{|l|l|l|l|l|}
\hline Source of variation & Degree of freedom & Sum Of squares & Mean square & F Report \\
\hline Model & 9 & 150.33081 & 16.7034 & 15.4676 \\
\hline Residue & 8 & 8.63919 & 1.0799 & Prob. $>$ F \\
\hline Total & 17 & 158.97000 & & 0.0004 \\
\hline
\end{tabular}

\section{Estimation of model Coefficients}

The significance of each coefficient was determined using the F-test and p-value given by JMP 7 software. A p-value less than 0.05 indicate the significance of an effect at $95 \%$ confidence level ${ }^{21}$. The significant effects and their coefficients are shown in (Table 5). The effects coefficients of the model showed that the decarbonization residues were significantly affected by the concentration $\left(\mathrm{X}_{1}\right)$ and the quadratic term of concentration $\left(X_{11}\right)$ at a risk $\alpha=$ 0.05 , the other factors and their effects were not significant, their p-values were larger than 0.05 , we can neglect their coefficients from the equation of the decarbonization residues. The fitted quadratic model for decarbonization residues was given by equation (4). The equation of the established model shows that the concentration has a negative effect, which means that the increase in this factor gives a decrease in the residue rate.

$\mathrm{Y}=68.049-2.744 * \mathrm{X}_{1}+1.874 * \mathrm{X}_{1}^{2}$

Table 5. Graph of the effect of different factors.

\begin{tabular}{|c|c|c|c|c|c|}
\hline Terme & Estimation & $\begin{array}{c}\text { Standard } \\
\text { error }\end{array}$ & Report t & Report t & Prob. $>|t|$ \\
\hline Constante & 68.049219 & 0.518828 & 131.16 & & $<.0001$ \\
\hline Concentration & -2.744919 & 0.281201 & -9.76 & $\sqsubset$ & $<.0001 *$ \\
\hline Concentration*Concentration & 1.8743979 & 0.292187 & 6.42 & $\begin{array}{cc}-1 & =1\end{array}$ & $0.0002 *$ \\
\hline Ratio & -0.111665 & 0.281201 & -0.40 & 11 & 0.7017 \\
\hline Concentration*Ratio & -0.095 & 0.367406 & -0.26 & I & 0.8025 \\
\hline Time & -0.066733 & 0.281201 & -0.24 & I & 0.8184 \\
\hline Ratio* Ratio & 0.0659723 & 0.292187 & 0.23 & 11 & 0.8270 \\
\hline Concentration*Time & -0.075 & 0.367406 & -0.20 & I & 0.8433 \\
\hline Time* Ratio & -0.0475 & 0.367406 & -0.13 & I & 0.9003 \\
\hline Time*Time & 0.0376881 & 0.292187 & 0.13 & ] & 0.9006 \\
\hline
\end{tabular}

* Significant at the level $95 \%$.

\section{Optimization using Desirability function}

In numerical optimization, we chose the desired goal for each factor and response. The possible goals were: to maximize, minimize, target, within range, none (for responses only) and set to an exact value (factors only). A minimum and a maximum level must be provided for each parameter included. A weight can be assigned to each goal to adjust the shape of its particular desirability function. The goals 
are combined into an overall desirability function. Desirability is an objective function that ranges from zero outside of the limits, to one at the goal. The program seeks to maximize this function. The goal seeking begins at a random starting point and proceeds up the steepest slope to a maximum. There may be two or more maximums because of curvature in the response surfaces and their combination in the desirability function. Starting from several points in the design space improves the chances of finding the 'best' local maximum ${ }^{22-25}$. The optimal condition of decarbonization residue determined using JMP 7 Software was represented in (Figure 2). It illustrates a case study where we set the goal at $68.18 \%$ with a concentration of $2 \mathrm{~mol} / \mathrm{l}$. Then varied the other parameters in the field of study using the prediction profiler which obtained the values of the other input factors: the treatment time is equal to $120 \mathrm{~min}$, and the ratio is equal to 10.02 .

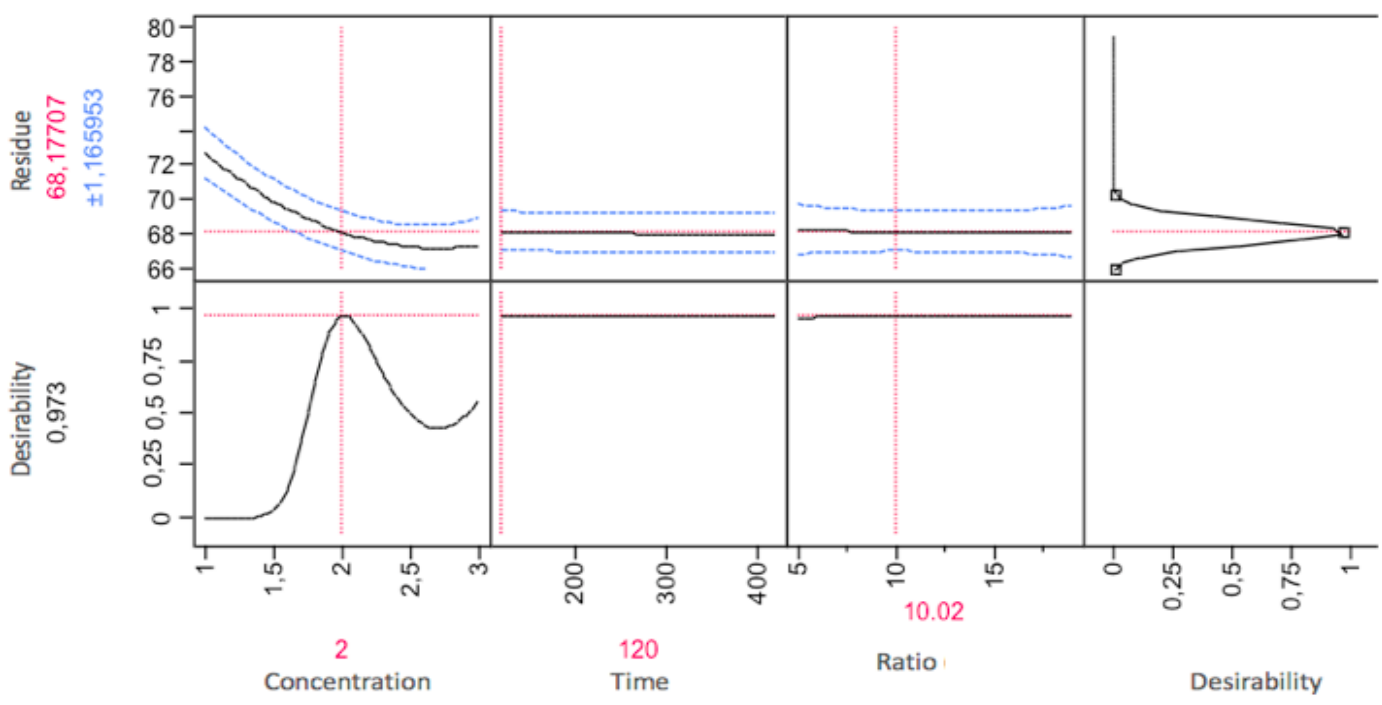

Figure 2. Profiles for predicted values and desirability function of decarbonization residues

\section{Three-dimensional response surface}

Three-dimensional (3D) for the measured response, was formed based on the model polynomial functions, to assess the change of the response surface ${ }^{26}$, and the relationship between the variables can be further understood ${ }^{27}$. It is a method to visualize the relationship between responses and experimental levels of each variable and the type of interactions between variables. The validated model can be plotted in a three-dimensional graph and generate a surface response that corresponds to the response function used for determination of the best conditions for a response. Since the model has three factors, one factor was held constant for each diagram. The plot of response surface (3D) presented by (Figure 3), shows the effect of concentration (X1) and time (X2) on the response. According to the plot (3D), an increase in concentration reduces the capacity of decarbonization.

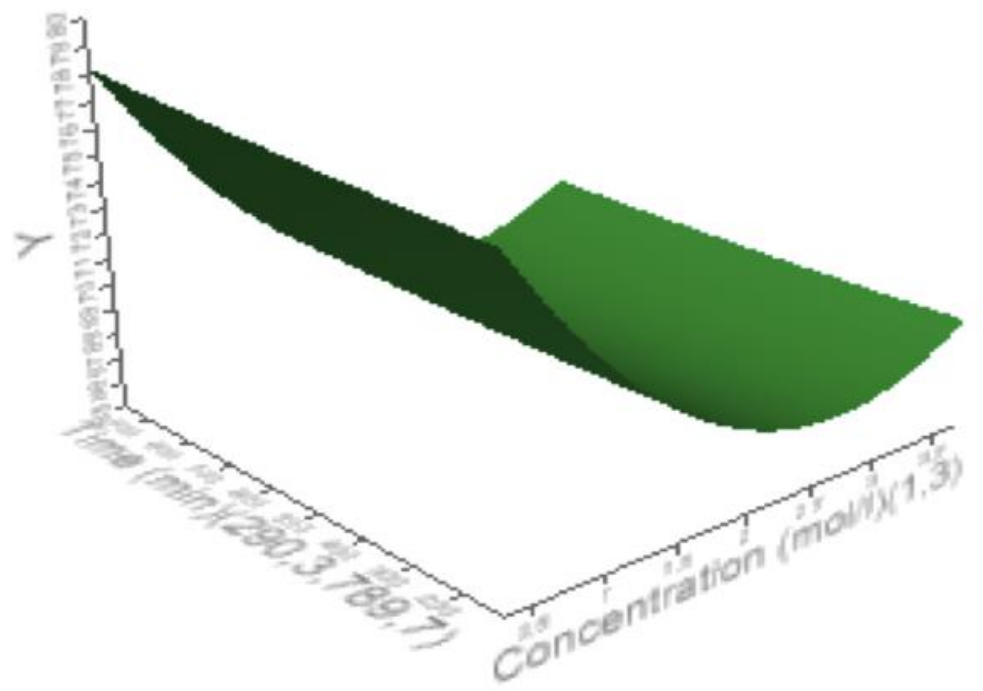

Figure 3. Response surface result of quadratic model (3D) 


\section{Characterization}

\section{Scanning electron microscopy (SEM) analysis}

The SEM images of raw and optimized materials are shown in (Figure 4). By comparing the SEM images of the two different samples, we can conclude morphological evolution during

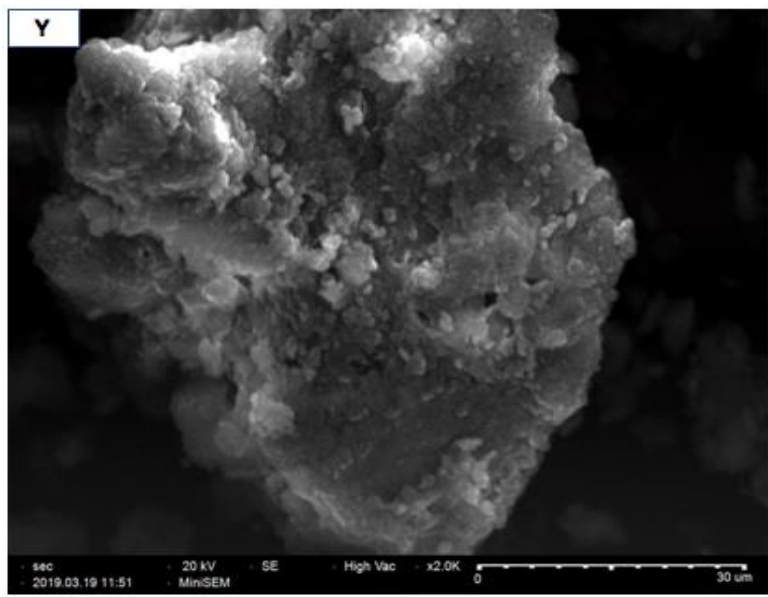

decarbonization. The Sample $\mathrm{Y}$ has a compact surface structure, while the texture of YO shows cracks and breaks, which can be attributed to the release of a large amount of carbon dioxide formed during decarbonization using acetic acid. However, most pores of oil shale are not yet fully open.

Figure 4. SEM image of the raw and optimized materials

\section{X-ray diffraction (XRD) analysis}

The results of the XRD analysis of the raw material (Y) of Timahdit oil shale show that the main inorganic compounds identified are calcite, quartz, dolomite, pyrite and clay (mica, illite, kaolinite, and montmorillonite) (Figure 5). Depending on the relative height of the peaks, calcite is the most abundant mineral in the sample (maximum peak around $2 \theta=29.5^{\circ}$ ). After calcite, quartz is the

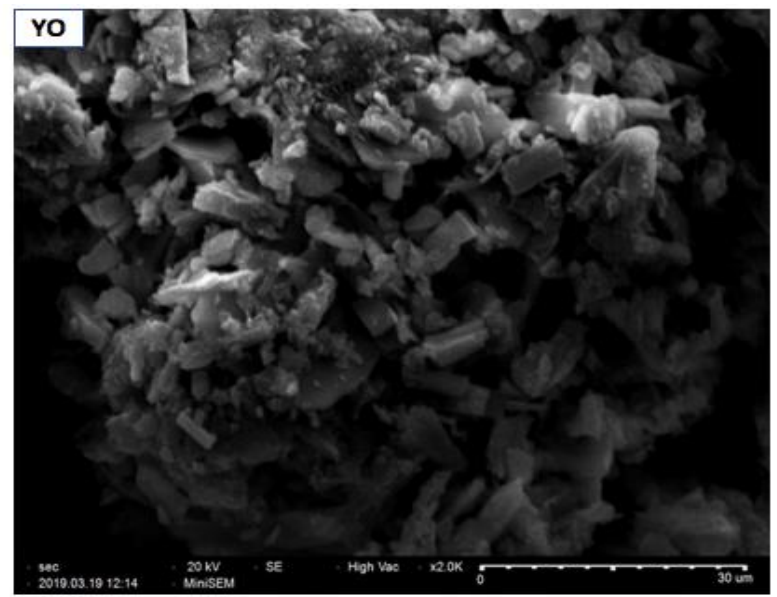

second dominant mineral. On the other hand, in the decarbonized sample (Figure 4), the calcite was eliminated by the attack of acetic acid, as confirmed by the disappearance of the peak at $2 \theta=29.5^{\circ}$. In the YO sample, the peaks characteristic of quartz, dolomite, silicate and clay mineral were not removed, indicating that acetic acid only removes calcite.

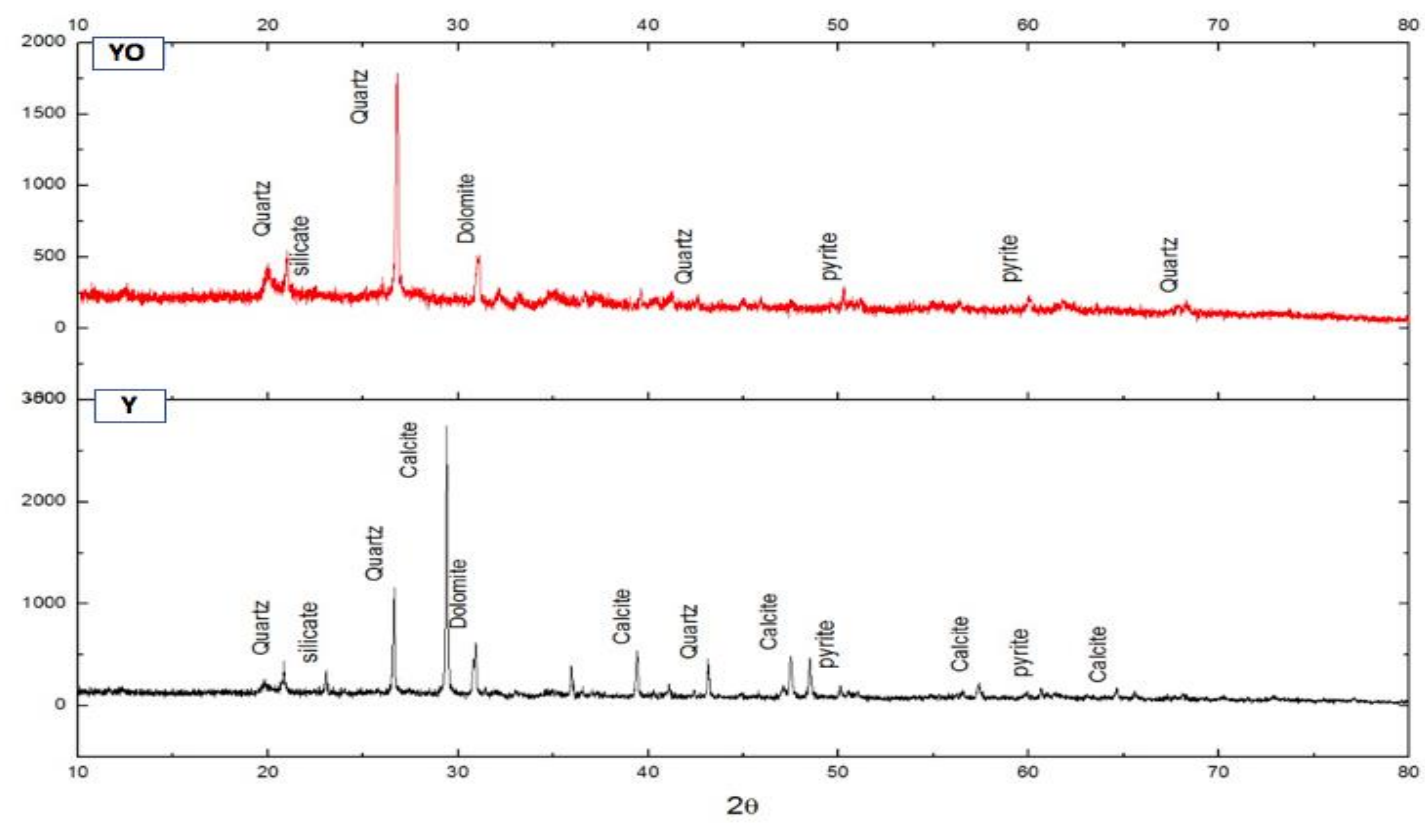

Figure 5. XRD patterns of the raw and optimized materials 


\section{X-ray fluorescence (XRF) analysis}

The results of XRF analysis are presented in (Table 6) and (Table 7). In agreement with the XRD data, the results of the XRF analysis of the Y sample indicate the presence of calcite as a main carbonate mineral $(37.40 \%$ by weight) (Table 7$)$, the $\mathrm{CaO}$ content is very high compared to the very low $\mathrm{MgO}$ content $\left(2.15 \%\right.$ by weight). The $\mathrm{SiO}_{2}$ content is
$28.56 \%$ by weight, indicating the presence of silica or quartz.

While the mineralogical composition of the YO sample differs significantly from the raw sample, YO contains fewer carbonates $(13 \%)$ and more silicates $(39.53 \%)$. The results of mineral elements (Table 6) show that crude oil shale is enriched in calcium $(\mathrm{Ca})$, silicon $(\mathrm{Si})$, sulfur $(\mathrm{S})$, aluminum $(\mathrm{Al})$, iron $(\mathrm{Fe})$.

Table 6. XRF results of the elements selected of Timahdit oil shale.

\begin{tabular}{|l|l|l|l|l|l|l|l|l|l|l|}
\hline Element & $\mathrm{Mg}$ & $\mathrm{Al}$ & $\mathrm{Si}$ & $\mathrm{P}$ & $\mathrm{S}$ & $\mathrm{Cl}$ & $\mathrm{k}$ & $\mathrm{Ca}$ & $\mathrm{Ti}$ & $\mathrm{Fe}$ \\
\hline Y (\%) & 0.912 & 3.543 & 10.251 & 0.795 & 4.264 & 0.22 & 1.402 & 26.123 & 0.522 & 3.627 \\
\hline YO (\%) & 0.808 & 4.149 & 12.591 & 0.837 & 5.481 & 2.402 & 1.942 & 8.393 & 0.596 & 3.948 \\
\hline
\end{tabular}

Table 7. XRF results of the Compounds of Timahdit oil shale

\begin{tabular}{|l|l|l|l|l|l|l|l|l|l|}
\hline Compound & $\mathbf{M g O}$ & $\mathbf{A l}_{2} \mathbf{O}_{3}$ & $\mathrm{SiO}_{2}$ & $\mathbf{P}_{\mathbf{2}} \mathbf{O}_{\mathbf{5}}$ & $\mathbf{S O}_{3}$ & $\mathrm{~K}_{2} \mathbf{O}$ & $\mathbf{C a O}$ & $\mathbf{T i O}_{2}$ & $\mathrm{Fe}_{2} \mathbf{O}_{3}$ \\
\hline Y (\%) & 2.157 & 9.183 & 28.562 & 2.202 & 12.569 & 1.852 & 37.401 & 0.787 & 4.604 \\
\hline YO (\%) & 2.287 & 12.562 & 39.536 & 2.510 & 17.405 & 2.712 & 13.001 & 1.017 & 5.572 \\
\hline
\end{tabular}

\section{Conclusion}

In this work, the effect of each factor involved in the process of decarbonization was determined with the response surface methodology "central composite design (CCD)". This method allowed us to determine the optimum conditions of the factors influencing the decarbonization process, which are the concentration, the time and the ratio. The results of the optimization of the operating conditions allowed us to remove $68.17 \%$ of carbonate. The three parameters were set at a concentration $=2$ $\mathrm{mol} / \mathrm{l}$, a ratio $=10.12$, and a time $=120 \mathrm{~min}$. The results of characterization showed that the acetic acid used to remove carbonates affects the chemical composition and the texture evolution of the residues.

\section{Acknowledgements}

This work was supported by the University Hassan II of Casablanca and the University Mohammed VI Polytechnic.

\section{References}

1- H. Zhang, Z. Wang, J. He, E. Liu, W. Song, and $\mathrm{S}$. Li, Staged condensation of oil shale pyrolysis volatiles for preliminary dedust and fractionation of shale oil, J Anal Appl Pyrol, 2019, 139, 301-307.

2- S. Zendehboudi, and A. Bahadori, Shale Oil and Gas Handbook, Shale Oil, 2017, 193-230.

3- A. Reva, and A. Blinderman, Underground gasification of oil shale, Underground Coal Gasification and Combustion, 2018, 527-579.

4- R. Bouchta, Valorization studies of the Moroccan [sic] oil shales. Office Nationale de
Researches et Exploitations Petrolieres, 1984, 28.

5- A. Abourriche, A. Adil, M. Oumam, H. Hannache, R. Pailler, R. Naslain, and J.P. Pillot, New pitches with very significant maturation degree obtained by supercritical extraction of Moroccan oil shales, J Supercrit Fluid. 2008, 47, 195-199.

6- H. Zhan, M. Chen, K. Zhao, Y. Li, X. Miao, H. Ye, and W. Yue, The mechanism of the terahertz spectroscopy for oil shale detection, Energy, 2018, 161, 46-51.

7- V.R. Bansal, R. Kumar, M.I.S. Sastry, R.M. Badhe, G.S. Kapur, and D. Saxena, Direct estimation of shale oil potential by the structural insight of Indian origin kerogen, Fuel, 2019, 241, 410-416.

8- C. Liang, Z.X. Jiang, Y.C. Cao, J. Wu, Y.S. Wang, and F. Hao, Sedimentary characteristics and origin of lacustrine organic-rich shales in the salinized Eocene Dongying Depression, GSA Bulletin, 2018, 130: 154-174.

9-J. Li, S. Lu, L. Xie, J. Zhang, H. Xue, P. Zhang, and S. Tian, Modeling of hydrocarbon adsorption on continental oil shale: A case study on n -alkane, Fuel, 2017, 206, 603-613.

10- M. Thomas, T. Partridge, B.H. Harthorn, and N. Pidgeon, Deliberating the perceived risks. benefits and societal implications of shale gas and oil extraction by hydraulic fracturing in the US and UK, Nature Energy, 2017, 2, 17054.

11- L. Chen, L. Zuo, Z. Jiang, S. Jiang, K. Liu, J. Tan, and L. Zhang, Mechanisms of shale gas adsorption: Evidence from thermodynamics and kinetics study of methane adsorption on shale, Chem Eng J, 2018. 
12- Y.P. Huang, C.H. Hou, H.C. His, and J.W. Wu, Optimization of highly microporous activated carbon preparation from Moso bamboo using central composite design approach, J Taiwan Inst Chem E, 2015, 50, 266-275.

13- R. Kumar, N. Singh, K. Kumar, N. Bishnoi, and R. Bishnoi, Response surface methodology approach for optimization of biosorption process for removal of $\mathrm{Cr}$ (VI) $\mathrm{Ni}$ (II) and $\mathrm{Zn}$ (II) ions by immobilized bacterial biomass $\mathrm{sp}$ Bacillus brevis, Chem Eng J, 2009, 146, 401-407.

14- O. Martins, Omorogie, B. Eliazer, Naidoo, and E. Augustine, Ofomaja, Response surface methodology. central composite design process methodology and characterization of pyrolyzed $\mathrm{KOH}$ pretreated environmental biomass: mathematical modeling and optimization approach, Modeling Earth Systems and Environment, 2017, 3, 11711186.

15- B. Sadhukhan, K. Mondal, and S. Chattoraj, Optimisation using the central composite design (CCD) and the desirability function for sorption of methylene blue from aqueous solution onto Lemna major, Karbala

International Journal of Modern Science, 2016, 145-155.

16- M. Ghaedi, and S.N. Kokhdan, Removal of methylene blue from aqueous solution by wood millet carbon optimization using response surface methodology, Spectrochimica Acta Part A: Molecular and Biomolecular Spectroscopy, 2015, 136-141.

17- M. Tarbaoui, M. Oumam, N. Fakhfakh, B.El Amraoui, M.Benzina, A. Bennamara, M. Charrouf, and A. Abourriche, Optimization of conditions for the preparation of new adsorbent material from residues of marine sponges using experimental design method, Anal Chem, 2015 15, 054-064.

18- S.K. Behera, H. Meena, S. Chakraborty, and B.C. Meikap, Application of response surface methodology (RSM) for optimization of leaching parameters for ash reduction from low-grade coal, Int J Mining Sci and Tech, 2018, 28, 621-629.

19- M. Tuzen, A. Sarı, and T.A. Saleh, Response surface optimization kinetic and thermodynamic studies for effective removal of rhodamine $\mathrm{B}$ by magnetic $\mathrm{AC} / \mathrm{CeO} 2$ nanocomposite, J Environ Manage, 2018, 206, 170-177.

20- R.H. Myers, D.C. Montgomery, and C. Anderson-Cook, Response Surface Methodology: Process and Product Optimization Using Designed Experiments. Wiley S Pro, 2015, 704.

21-A.I. Khuri, S. Mukhopadhyay, Response surface methodology, Wires Comput Stat, 2010.

22- S. Chattoraj, N.K. Mondal, B. Das, P. Roy, B. Sadhukhan, Biosorption of carbaryl from aqueous solution onto Pistia stratiotes biomass, Applied Water Science, 2014, 4, 79-88.

23- S. Senthilkumaar, P. Kalaamani, and C.V. Subburaam, Liquid-phase adsorption of Crystal violet onto activated carbons derived from male flowers of the coconut tree, J Hazard Mater, 2006, 136, 800-808.

24- P. Saha, S. Chowdhury, S. Gupta, I. Kumar, R. Kumar, Assessment on the removal of malachite green using tamarind fruit shell as biosorbent, Clean Soil Air Water, 2010, 38, 437-445.

25- A. Gadhe, S.S. Sonawane, M.N. Varma, Optimization of conditions for hydrogen production from complex dairy wastewater by anaerobic sludge using desirability function approach, Int J Hydrogen Energ, 2013, 38, 6607-6617.

26- F. Divsar, K. Habibzadeh, and S. Shariati, Aptamer-conjugated silver nanoparticles for the colorimetric detection of arsenic ions using response surface methodology. Anal. Methods, 2015, 7(11), 4568-4576.

27- MA. Bezerra, RE. Santelli, and EP. Oliveira, Response surface methodology (RSM) as a tool for optimization in analytical chemistry. Talanta, 2008, 76(5), 965- 977. 